\title{
Structural, thermal, and optical analysis of zinc boro-aluminosilicate glasses containing different alkali and alkaline modifier ions
}

\begin{abstract}
In this article, structural, thermal, and optical properties of zinc boro-aluminosilicate glasses with addition of different alkali ( $\mathrm{Li}, \mathrm{Na}$, and $\mathrm{K}$ ) and alkaline oxides $(\mathrm{Mg}, \mathrm{Ca}, \mathrm{Sr}$, and $\mathrm{Ba}$ ) have been reported. $10 \mathrm{~mol} \%$ of alkali and alkaline oxides were incorporated into Zinc boroaluminosilicate glasses and all these glasses possess high optical quality. Samples were characterized using X-ray diffraction (XRD), scanning electron microscopy and energy dispersive X-ray analysis (SEM-EDAX), attenuated total reflectance-Fourier transform infrared (ATR-FTIR) spectroscopy, Raman spectroscopy, thermo-gravimetric analysis (TGA), differential scanning calorimetry (DSC), and optical absorption spectroscopy. The $\mathrm{XRD}$ and SEM measurements demonstrated the amorphous origin for all the prepared glasses and EDAX confirms that all the elements are presented in the prepared glasses. The presence of various functional groups such as triangular and tetrahedral-borate $\left(\mathrm{BO}_{3}\right.$ and $\left.\mathrm{BO}_{4}\right)$ was confirmed by ATR-FTIR and Raman spectra, and both of the ATR-FTIR and Raman spectra show lower phonon energy for $\mathrm{H} 3\left(\mathrm{~K}_{2} \mathrm{O}\right)$ in alkali series, and $\mathrm{H} 7(\mathrm{BaO})$ for alkaline. From TGA analysis we found a lower weight loss $<0.1 \%$ in $\mathrm{K}_{2} \mathrm{O}, \mathrm{MgO}$, and $\mathrm{BaO}$; and from the DSC profiles the glass transition temperature $\left(T_{g}\right)$, onset crystallization temperature $\left(T_{x}\right)$, crystallization temperature $\left(T_{c}\right)$, and melting temperature $\left(T_{m}\right)$ were identified and related different thermal parameters are evaluated. Alkali and alkaline influenced Zinc boroaluminosilicate glasses demonstrate excellent glass stability. From the optical absorption spectra, we calculated cut-off wavelength and it shows spectral shifting to longer wavelength with alkali $(\mathrm{Li} \rightarrow \mathrm{Na} \rightarrow \mathrm{K}$ ), and alkaline $(\mathrm{Mg} \rightarrow \mathrm{Ca} \rightarrow \mathrm{Sr} \rightarrow \mathrm{Ba}$ ) modifiers. We investigated optical band gap energy also for allowed transitions in UV-visible region using three methods; direct, indirect, and absorption spectrum fitting (ASF).
\end{abstract}

Keyword: Zinc boro-aluminosilicate glasses; X-ray diffraction; Fourier transform infrared spectroscopy; Raman spectroscopy; Thermal analysis; Optical absorption 
